\title{
Synchronous Akinete Germination and Heterocyst Differentiation in Anabaena PCC 7937 and Nostoc PCC 6720
}

\author{
By S. C. SKILL AND R. J. SMITH* \\ Department of Biological Sciences, University of Lancaster, Bailrigg, Lancaster LA1 4YQ,UK
}

(Received 18 July 1986; revised 5 September 1986)

\begin{abstract}
Isolates of the filamentous cyanobacteria Anabaena PCC 7937 and Nostoc PCC 6720 were selected in which the germling extruded from the akinete coat at the single cell stage and in which heterocyst differentiation occurred at the two or three cell stage after germination in the absence of combined nitrogen. The process of heterocyst differentiation of these germinating akinetes was synchronous and highly reproducible, and it resulted in transient yields of mature heterocysts exceeding $35 \%$ of the total cell population.
\end{abstract}

\section{INTRODUCTION}

The vegetative cells of certain filamentous cyanobacteria differentiate to form heterocysts, which are specialized cells providing a microaerobic environment necessary for $\mathrm{N}_{2}$ fixation. Apart from the agronomic importance of heterocysts, due to their role in $\mathrm{N}_{2}$ fixation in the presence of air, there is increasing interest in heterocyst development as a model for a cytodifferentiation process (Haselkorn, 1978; Carr, 1979). The changes leading to heterocyst differentiation are complex. In the absence of combined nitrogen, vegetative cell division precedes the development of certain daughter cells into immature proheterocysts. Further development yields mature heterocysts containing nitrogenase and capable of $\mathrm{N}_{2}$ fixation. Both of these developmental stages involve commitment steps after which the differentiating cell is unable to revert to the vegetative state (Bradley \& Carr, 1976, 1977).

The proportion of heterocysts induced by deprivation of combined nitrogen in vegetative cultures is about $8 \%$ of the total cell population. Various treatments, such as low concentrations of rifampicin and 7-azatryptophan, increase this proportion, but the modes of action of these compounds are unknown (Mitchison \& Wilcox, 1973; Stacey et al., 1979; Wolk \& Quine, 1975). A purely physical approach, fragmentation of filaments before heterocyst induction, also yields high heterocyst frequencies (10-15\%) (Van de Water \& Simon, 1982; Jüttner, 1983). This communication describes the isolation and characterization of isolates of Anabaena PCC 7937 and Nostoc PCC 6720 yielding a transient heterocyst frequency of up to 30-38\% upon germination of the akinetes in the absence of combined nitrogen.

\section{METHODS}

Strains and culture conditions. Anabaena PCC 7937 (Anabaena variabilis) and Nostoc PCC 6720 (formerly known as Anabaenopsis circularis: Rippka et al., 1979) were obtained from the Pasteur Culture Collection, Paris, France. Strains were maintained either on $1 \%(\mathrm{w} / \mathrm{v})$ agar slopes prepared in the medium of Allen \& Arnon (1955) or as pelleted material stored in liquid $\mathrm{N}_{2}$. Stock cultures were grown at $30^{\circ} \mathrm{C}$ in an eightfold dilution of the medium (AA/8) in an illuminated rotary incubator (LH Fermentation) at a mean light intensity of $50 \mu \mathrm{E} \mathrm{m} \mathrm{m}^{-2} \mathrm{~s}^{-1}$.

Akinete preparation. Akinetes were prepared from 8 litre batch cultures (transparent plastic carboys) in modified AA/8 medium; phosphate concentration was reduced to $0.4 \mu \mathrm{M}$ and the medium was buffered to $\mathrm{pH} 7.8 \mathrm{with} 0.3 \mathrm{~g}$ HEPES $1^{-1}$. Cultures were incubated at $30^{\circ} \mathrm{C}$, gassed with air and illuminated with fluorescent light of intensity $100 \mu \mathrm{E} \mathrm{m}^{-2} \mathrm{~s}^{-1}$. Growth was monitored as $\mathrm{OD}_{650}$ and the purity of the cultures was checked according to Rippka et al. (1979). The cultures entered the stationary phase at $\mathrm{OD}_{650} 0.8$ and were allowed to grow for a further 3-5d, 
by which time the majority of the filaments were composed of akinetes. The cultures were placed at room temperature without gassing or artificial light for a further day, or longer, until the akinetes had settled to the bottom of the container.

The clear supernatant was aspirated and the residual concentrated akinete suspension was transferred to a sterile flask. The suspension was pelleted and washed twice with fresh growth medium using a fixed blade blender for $20 \mathrm{~s}$. This treatment dispersed any remaining filaments. Washed akinetes were stored at $4{ }^{\circ} \mathrm{C}$ until required.

Isolate selection. Filaments produced by the germination of a single akinete were picked from $1 \%$ agar and incubated in AA/8 medium until mature akinetes developed. Microscopic examination allowed selection of isolates in which the germling emerged from the akinete coat at the single cell stage. The extrusion of the germling from the akinete coat was impaired by prolonged storage of the preparation in excess of 12 weeks at $4{ }^{\circ} \mathrm{C}$.

Akinete germination. Akinetes were resuspended to $\mathrm{OD}_{650} 0.4$ in $\mathrm{AA} / 8$ low-phosphate medium and gassed with air under fluorescent illumination $\left(190 \mu \mathrm{E} \mathrm{m}^{-2} \mathrm{~s}^{-1}\right)$. Combined nitrogen was omitted from the growth medium if heterocyst differentiation was required.

Estimation of akinete viability and differentiating cells. The proportion of germinating akinetes was determined by examination of at least 500 akinetes or akinete equivalents (i.e. short trichomes composed of two to three cells) under the light microscope. Akinetes that did not emerge from their coat and remained in the single cell stage were considered to be inviable. The numbers of proheterocysts and heterocysts were recorded and expressed as a percentage of the total cell population derived from the germinated akinetes. The commitment times for cellular differentiation were determined as described by Bradley \& Carr $(1976,1977)$.

Determinations. Chlorophyll $a$ was measured according to Sutherland et al. (1979) and nitrogenase activity was measured by the acetylene reduction technique (Stewart et al., 1968).

\section{RESULTS AND DISCUSSION}

Cell division precedes heterocyst differentiation and, from an early stage of development, the heterocyst represses differentiation of adjacent vegetative cells (Wilcox, 1970). Furthermore, heterocysts depend on the vegetative cells for a supply of carbon and reducing power (Jüttner, 1983). It follows that the maximum proportion of heterocysts one could expect would be $50 \%$. Such a yield should arise from single cell cultures in which one of the daughter cells from the first cell division undergoes differentiation. In this case the intercellular zone of inhibition attributable to each heterocyst is reduced to the minimum. The increase of heterocyst frequency after filament fragmentation (Van de Water \& Simon, 1982; Jüttner, 1983) is in support of this theory. Unfortunately, unicellular cultures are not readily obtained from filamentous cyanobacteria. A natural source of a single cell stage of many filamentous cyanobacteria is known as the akinete (Sutherland \& Herdman, 1979; Sutherland et al., 1979; 1985a,b). The germlings of many species undergo cell division and heterocyst differentiation within the akinete coat (Nichols \& Adams, 1982), which might not be desirable for certain types of experiments. However, isolates of Anabaena PCC 7937 and Nostoc PCC 6720 were obtained in which the germlings extrude from their envelopes at the single cell stage. This property was maintained over successive generations. Braune (1980) demonstrated similar properties with isolates of Anabaena variabilis JS/07. The frequency with which the natural variants with altered germination properties occurred was $5 \%$ in both strains: $10 \%$ of these isolates maintained the desired properties in liquid culture. These isolates were designated Nostoc PCC $6720 \mathrm{SC} / *$ and Anabaena PCC $7937 \mathrm{SC} / *$ (* represents isolate number). Further isolates are presently being prepared. The isolates used in this study were Nostoc PCC 6720 SC/16 and Anabaena PCC 7937 $\mathrm{SC} / 09$.

With akinetes derived from the Nostoc isolates, about $85-90 \%$ of the akinete population germinated (Fig. 1). Polar degradation of the akinete spore coat was first noted at $1-5 \mathrm{~h}$ after akinete resuspension and was taken as the criterion for the start of akinete germination (Fig. 2). Subsequent division was quite synchronous and reproducible: $80-90 \%$ of the germinated akinetes underwent cell division between 8 and $10 \mathrm{~h}$, this process being essentially completed after $12 \mathrm{~h}$ (Fig. 1). The remaining akinetes that had initiated germination stayed at the single cell stage. The majority of the germlings completely emerged from the spore coat. A small proportion, around $5 \%$, remained attached to the coat in a partially emerged state. Empty spore coats accumulated in the culture medium. 


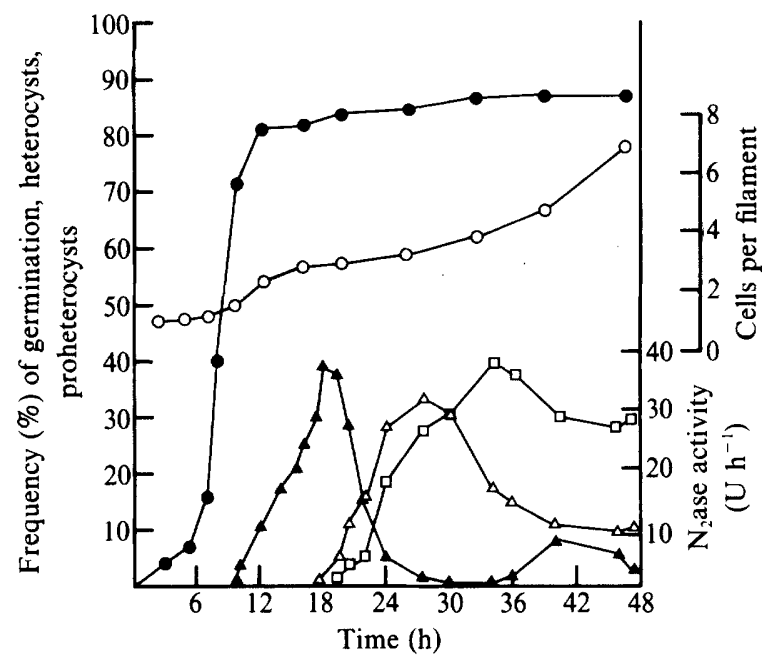

Fig. 1. Germination of akinetes of Nostoc PCC 6720 SC/16. - Germination frequency; $\triangle$, heterocyst frequency; $\Delta$, proheterocyst frequency; $\square$, nitrogenase activity $\left[1 \mathrm{U}=1 \mu \mathrm{mol} \mathrm{C}_{2} \mathrm{H}_{4}\right.$ (mg chlorophyll $a^{-1}$ ]; $O$, mean number of cells per filament derived from a germinating akinete.
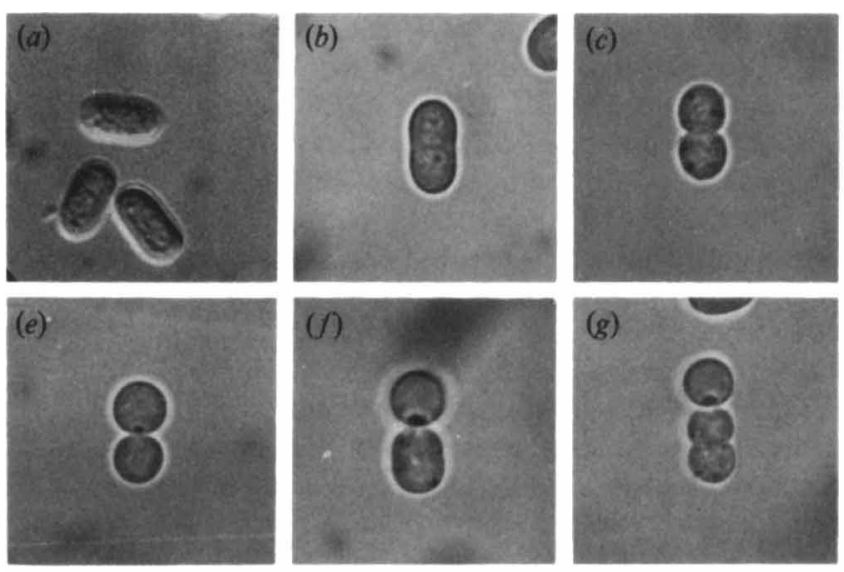
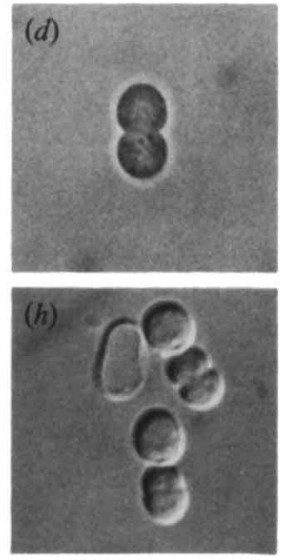

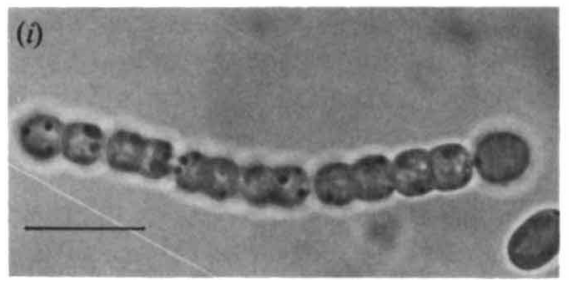

Fig. 2. Phase contrast micrographs of Nostoc PCC 6720, showing the stages of heterocyst differentiation after akinete germination in the absence of combined nitrogen. The akinetes $(a)$ germinate to extrude single cells, which divide $(b)$ to yield two-celled filaments $(c)$. One of these daughter cells differentiates; an early characteristic is the loss of granulation (upper cell, $d$ ) followed by rounding of the differentiating cells, the formation of a thickened rounded cell wall and the beginning of plug deposition (upper cell, $e$ ). This proheterocyst matures to form a heterocyst distinguished by the fully-formed plug $(f)$. Cell division of the vegetative cell proceeds during the differentiation so that the culture contains a mixture of two and three celled filaments $(f, g$ and $h)$. After maturation of the heterocyst, vegetative cell division continues until filaments $10-12$ cells in length arise $(i)$. Magnification is the same in all micrographs. The bar marker $(i)$ is equivalent to $10 \mu \mathrm{m}$. 


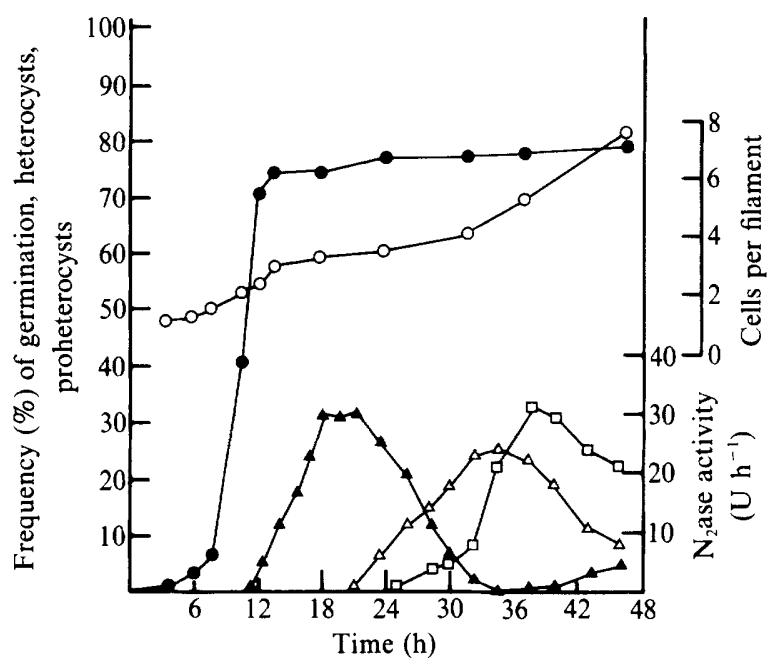

Fig. 3. Germination of akinetes of Anabaena PCC 7937 SC/09. Germination frequency; $\triangle$, heterocyst frequency; $\Delta$, proheterocyst frequency; $\square$, nitrogenase activity $\left[1 \mathrm{U}=1 \mu \mathrm{mol} \mathrm{C}_{2} \mathrm{H}_{4}(\mathrm{mg}\right.$ chlorophyll $a)^{-1}$; $\bigcirc$, mean number of cells per filament derived from a germinating akinete.

Proheterocysts first appeared at 10-11 h in filaments of two cells in which one daughter cell had commenced differentiation. The relative proportion of proheterocysts to the total cell population reached a peak (40-45\%) after $17-19 \mathrm{~h}$, by which time the average filament length was approximately 2.5 cells. Proheterocyst content declined with the increase in mature heterocysts, which reached a frequency of $35-38 \%$ after $28 \mathrm{~h}$. At this stage the average filament length was about 2.9 cells and the proheterocyst content had declined to zero. $\mathrm{N}_{2}$ fixation, as judged by $\mathrm{C}_{2} \mathrm{H}_{2}$ reduction, began at $18-20 \mathrm{~h}$ and increased in parallel with the increase in mature heterocysts to reach a peak at $30-35 \mathrm{~h}$. Continued vegetative cell division between 28 and $40 \mathrm{~h}$ reduced the heterocyst content of the culture to $10 \%$. Proheterocysts were absent from the culture until about $36 \mathrm{~h}$, when the second round of heterocyst differentiation began in the terminal cells of the filaments at the opposite end to the first mature heterocyst. The heterocyst content subsequently declined slowly toward $7-8 \%$.

Akinetes derived from an Anabaena isolate were germinated as above (Fig. 3). The profile of heterocyst differentiation was similar to that obtained for the Nostoc isolate, though the proportion of akinetes that germinated was $70-80 \%$ of the total and the maximum heterocyst frequency was $25-30 \%$. The synchrony of proheterocyst and heterocyst differentiation was inferior to that seen in Nostoc.

The progressive acquisition of heterocyst-specific physiological characteristics (Lang, 1965) and proteins (Fleming \& Haselkorn, 1974) during differentiation implies that a series of molecular events precedes heterocyst formation. As a means of defining the start and completion of these events, Bradley \& Carr (1977) proposed the determination of commitment times for both proheterocyst and heterocyst differentiation. Nitrate $(10 \mathrm{mM})$ or rifampicin $\left(0.2 \mu \mathrm{g} \mathrm{ml}^{-1}\right)$, were added at time intervals after the suspension of the akinetes in medium free of combined nitrogen and the presence of proheterocysts and heterocysts in these samples was compared to controls $48 \mathrm{~h}$ after akinete resuspension. These provide a guide to the timing of events leading to the formation of the two cell types. Similarly, the presence of active nitrogenase heralds the presence of functionally mature heterocysts and the completion of the differentiation phase (Figs 1 and 3). The commitment times observed were similar to those for heterocyst differentiation from vegetative cultures (data not shown). For Nostoc, the commitment times for proheterocysts and heterocysts were $7.5-8.5 \mathrm{~h}$ and $11-12 \mathrm{~h}$ respectively for nitrate addition, and $5 \cdot 5-6.5 \mathrm{~h}$ and $10-11 \mathrm{~h}$ respectively for rifampicin addition. For Anabaena, these values were $8-9.5 \mathrm{~h}$ and $11.5-12.5 \mathrm{~h}$ with nitrate, and $6-7.5 \mathrm{~h}$ and $10.5-12 \mathrm{~h}$ with rifampicin. 
We have shown that it is possible to obtain heterocyst frequencies of $35-40 \%$ and $25-30 \%$ with germinating akinetes of Nostoc PCC 6720 and Anabaena PCC 7937 isolates respectively, which is higher than previously published reports for these strains. The yields of heterocysts and proheterocysts produced by germinated akinetes, especially of the Nostoc isolates, would be of advantage for studies on heterocyst differentiation. Since the successive phases of differentiation do not overlap, this isolate would allow the preparation of well-defined cultures in which the filament length and the number of heterocysts, as well as their position in the filament, may be controlled.

We wish to thank Professor Peter Lea for critical reading of the manuscript and Mrs Ann Wilkins for helpful laboratory assistance. These experiments were done by S.C.S. in partial fulfilment of the PhD requirements of the University of Lancaster.

This work was supported by the Science and Engineering Research Council.

\section{REFERENCES}

Allen, M. B. \& ARnon, D. I. (1955). Studies on nitrogen-fixing blue green algae. I. Growth and nitrogen fixation by Anabaena cylindrica Lemm. Plant Physiology 30, 366-372.

Bradley, S. \& CARR, N. G. (1976). Heterocyst and nitrogenase development in Anabaena cylindrica. Journal of General Microbiology 96, 175-184.

Bradley, S. \& CarR, N. G. (1977). Heterocyst development in Anabaena cylindrica: the necessity of light as an initial trigger and sequential stages of commitment. Journal of General Microbiology 101, 291-297.

BRAUNE, W. (1980). Structural aspects of akinete germination in Anabaena variabilis. Archives of Microbiology 126, 257-261.

CARR, N. G. (1979). Differentiation in filamentous cyanobacteria. In Developmental Biology of Prokaryotes, pp. 167-201. Edited by J. H. Parish. Oxford: Blackwell Scientific Publications.

FLEMING, H. \& HASELKORN, R. (1974). The program of protein synthesis during heterocyst differentiation in nitrogen-fixing blue green algae. Cell 3, 159-170.

Haselkorn, R. (1978). Heterocysts. Annual Review of Plant Physiology 29, 319-344.

JÜTTNER, F. (1983). ${ }^{14} \mathrm{C}$ labelled metabolites in heterocyst and vegetative cells of Anabaena cylindrica filaments and their presumptive function as transport vehicles of organic carbon and nitrogen. Journal of Bacteriology 155, 628-633.

LANG, N. J. (1965). Electron microscopic study of heterocyst development in Anabaena azollae Strasburger. Journal of Phycology 1, 127-134.

Mitchison, G. J. \& Wilcox, M. (1973). Alteration in heterocyst pattern of Anabaena produced by 7azatryptophan. Nature New Biology 246, 229-233.

Nichols, J. M. \& ADAMS, D. G. (1982). Akinetes. In The Biology of the Cyanobacteria, pp. 387-412. Edited by N. G. Carr \& B. A. Whitton. Oxford: Blackwell Scientific Publications.

RipPKa, R., Deruelles, J., Waterbury, J. B., Herdman, M. \& Stanier, R. Y. (1979). Generic assignments, strain histories and properties of pure cultures of cyanobacteria. Journal of General Microbiology 111, 1-61.

Stacey, G., Van BaAlen, C. \& Tabita, F. R. (1979). Nitrogen and ammonia assimilation in the cyanobacteria: regulation of glutamine synthetase. $A r-$ chives of Biochemistry and Biophysics 194, 457-467.

Stewart, W. D. P., Fitzgerald, G. P. \& Burris, R. H. (1968). Acetylene reduction by nitrogen fixing blue green algae. Archives of Microbiology 62, 336348.

Sutherland, J. M. \& Herdman, M. (1979). Synchronised germination of cyanobacterial akinetes. In Proceedings of the Third International Symposium on Photosynthetic Prokaryotes, D24. Edited by J. M. Nichols. Liverpool: Liverpool University.

Sutherland, J. M., Herdman, M. \& Stewart, W. D. P. (1979). Akinetes of the cyanobacterium Nostoc PCC 7524: macromolecular composition, structure and control of differentiation. Journal of General Microbiology 115, 273-287.

Sutherland, J. M., Stewart, W. D. P. \& Herdman, M. (1985a). Akinetes of the cyanobacterium Nostoc PCC 7524: morphological changes during synchronous germination. Archives of Microbiology 142, 269274.

Sutherland, J. M., Reaston, J., Stewart, W. D. P. \& HeRdMan, M. (1985b). Akinetes of the cyanobacterium Nostoc PCC 7524: macromolecular and biochemical changes during synchronous germination. Journal of General Microbiology 131, 2855-2863.

VAN DE WaTER, S. D. \& Simon, R. D. (1982). Induction and differentiation of heterocysts in the filamentous cyanobacterium Cylindrospermum licheniforme. Journal of General Microbiology 128, 917-925.

WiLcoX, M. (1970). One-dimensional pattern found in blue green algae. Nature, London 228, 686-687.

Wolk, C. P. \& QuINe, M. P. (1975). Formation of onedimensional pattern by stochastic processes and by filamentous blue green algae. Developmental Biology 46, 370-382. 